\title{
Interleukin 1/1RA axis in colorectal cancer regulates tumor invasion, proliferation and apoptosis via autophagy
}

\author{
YUSHENG CHEN $^{1 *}$, ZHOU YANG $^{1 *}$, BO DENG $^{2 *}$, DEJUN WU $^{1}$, YINGJUN QUAN $^{3}$ and ZHIJUN MIN ${ }^{1}$ \\ ${ }^{1}$ Department of General Surgery, Shanghai Pudong Hospital, Fudan University Pudong Medical Center, \\ Shanghai 201399; ${ }^{2}$ Division of Nephrology, Shanghai Ninth People's Hospital, School of Medicine, \\ Shanghai Jiaotong University, Shanghai 200011; ${ }^{3}$ Department of General Surgery, Tongren Hospital, \\ Shanghai Jiao Tong University School of Medicine, Shanghai 200050, P.R. China
}

Received October 1, 2019; Accepted December 17, 2019

DOI: $10.3892 /$ or.2020.7475

\begin{abstract}
Interleukin (IL)-1 $\beta$ is a member of the IL-1 family of proteins. IL-1 receptor antagonist (IL-1RA) is an agent that binds to the IL-1 receptor, preventing IL-1 from transmitting signals to cells. The present study aimed to identify the role of the IL-1 $\beta / 1 \mathrm{RA}$ axis in epithelial-mesenchymal transition (EMT), cell invasion, migration, proliferation and clone formation in colorectal cancer (CRC) and to determine its underlying mechanisms of action. Significantly increased expression of both IL-1 $\beta$ and IL-1RA was identified in CRC patient data uploaded in The Cancer Genome Atlas database, and in tumor tissues when compared with matched control tissue. High expression of IL-1 $\beta$ was associated with an increased rate of overall survival and recurrence-free survival. Further research revealed that the IL-1 $\beta$ gene was co-expressed with the IL-1RA gene in tumors of CRC patients. It was additionally determined that recombinant human (rh)IL-1 $\beta$ suppressed autophagy as well as EMT in HCT-116 cells compared with control-treated cells, whereas rhIL-1RA exhibited the opposite effect. In addition, autophagy activator rapamycin (RAPA) rescued the inhibition of EMT in rhIL-1 $\beta$-treated HCT-116 cells. Moreover, rhIL-1 $\beta$ inhibited cell invasion, migration, proliferation and colony-formation ability, when compared with a control treatment. Compared
\end{abstract}

Correspondence to: Dr Zhijun Min, Department of General Surgery, Shanghai Pudong Hospital, Fudan University Pudong Medical Center, 2800 Gongwei Road, Huinan, Pudong, Shanghai 201399, P.R. China

E-mail:minzhijun@126.com

Dr Yingjun Quan, Department of General Surgery, Tongren Hospital, Shanghai Jiao Tong University School of Medicine, 1111 Xianxia Road, Shanghai 200050, P.R. China

E-mail: qyjasmine@126.com

${ }^{*}$ Contributed equally

Key words: interleukin 1 $\beta$, interleukin 1RA, autophagy, epithelial-mesenchymal transformation, colorectal cancer with a control treatment rhIL-1RA promoted cell invasion, migration, proliferation, but had no effect on clone formation ability. Furthermore, both rhIL-1RA and RAPA rescued inhibition of cell invasion, migration and clone formation ability in rhIL-1 $\beta$-treated HCT-116 cells. RAPA, but not rhIL-1RA, rescue inhibited proliferation in rhIL-1 $\beta$-treated HCT-116 cells compared with controls. In addition, it was confirmed that rhIL-1 $\beta$ inhibited the growth of subcutaneous xenografts in nude mice, when compared with control treatments. These results indicated that upregulation of the IL-1 $\beta / 1 \mathrm{RA}$ axis in $\mathrm{CRC}$ regulated EMT, cell invasion and migration, proliferation and clone formation via autophagy.

\section{Introduction}

Chronic inflammation promotes the development, growth and metastasis of cancer. Acute inflammation, if not controlled develops into chronic inflammation, which may increase the risk of cancer. Epidemiological studies have confirmed that $25 \%$ of tumors are developed from inflammation (1). Patients with the inflammatory autoimmune disease ulcerative colitis are 10 times more likely to develop colon cancer than healthy individuals (2).

The accumulation of inflammatory cells and inflammatory cytokines in the tumor microenvironment promotes malignant cell proliferation, metastasis and epithelial-mesenchymal transition (EMT), and can lead to the loss of the acquired immune response (3). The majority of cytokines are low molecular weight soluble proteins, which have many functions, such as regulating cell growth, hematopoiesis and the immune response and repairing damaged tissues (4). Cytokines can be divided into lymphokines, produced by lymphocytes, and mononuclear factors, produced by mononuclear macrophages. Interleukins (ILs), interferons, colony stimulating factors, tumor necrosis factors and transforming growth factors are all cytokines produced by immune cells, which play important regulatory roles in the immune system and can lead to pathological reactions when expressed at altered levels.

IL- $1 \beta$ is a member of the IL- 1 family of cytokines. IL- $1 \beta$ is produced by activated macrophages as a proprotein, which is proteolytically processed to its active form by caspase-1 (CASP1). CASP1 is an important mediator of the inflammatory 
response, and is involved in a variety of cellular activities, including cell proliferation, differentiation and apoptosis (5). A number of studies have determined that IL-1 $\beta$ also plays an important role in the occurrence and development of tumors. In breast cancer, IL-1 $\beta$ induces EMT and promotes disease relapse (6). In gastric cancer, IL-1 $\beta$-induced p38 pathway activation promoted cell invasion and migration via increased matrix metalloproteinase (MMP)2 and MMP9 expression (7). In addition, IL-1 receptor antagonist (IL-1RA) is an agent that binds to the cell surface IL-1 receptor (IL-1R), the same receptor that binds to IL-1 family members, preventing IL-1 from sending a signal to cells. A previous study suggested that serum concentrations of IL-1RA in colorectal cancer (CRC) patients were significantly higher than those in healthy patients, however, the specific role of IL-1RA in CRC has not been clarified (8).

In the present study, recombinant human (rh)IL-1 $\beta$ and rhIL-1RA were used to study the role of IL-1 $\beta$ and IL-1RA in CRC.

\section{Materials and methods}

Patients and specimens. CRC tumor specimens and paired non-tumor mucosa were collected between July 2012 and July 2018. Patients with the following criteria were excluded from participation in the study: i) The patient had received adjuvant chemotherapy or radiotherapy prior to surgery; ii) the patient had additional cancer diagnoses. All patients were classified according to the 7th edition of the TNM staging system 23. Postoperative adjuvant therapies were performed, according to standard schedules and doses. All participating patients provided their written informed consent. This study was approved by the Ethical Committee of Shanghai Pudong Hospital. Patient details are summarized in Table I.

TCGA database and analysis. TCGA-Colon Adenocarcinoma (https://cancergenome.nih.gov/) contains 480 colon cancer cases and 41 normal control cases, accompanied with clinical characteristics. All mRNA expression data accompanied by clinical data was downloaded by R-software for subsequent analysis. The expression of IL-1 $\beta$ and IL-1RA in CRC were analyzed by UALCAN web tools based on the TCGA database (9) (http://ualcan.path.uab.edu/). Co-expression, overall survival (OS) and recurrence-free survival (RFS) of IL-1 $\beta$ and IL-1RA genes were identified via GEPIA web tools based on TCGA database (10) (http://gepia.cancer-pku.cn/).

Immunohistochemical (IHC) staining. IHC staining was carried out according to the antibody manufacturers' instructions. Briefly, formalin-fixed and paraffin-embedded tissue sections were deparaffinized in xylene and hydrated with decreasing concentrations of ethanol (100, 95, 80 and 75\%). The slices were then soaked in $10 \%$ BSA to inhibit endogenous peroxidase activity and incubated with IL-1 $\beta$ and IL-1RA rabbit polyclonal antibody (dilution 1:100; cat. nos. AF-201 and AF-280; R\&D Systems, Inc.) at $4^{\circ} \mathrm{C}$ overnight. A horseradish peroxidase-conjugated rabbit secondary antibody (cat. no. ab6721; Abcam) was added for $60 \mathrm{~min}$ at room temperature; then, 3,3'-diaminobenzidine development (DAB Substrate Chromogen System; Dako; Agilent Technologies,
Table I. Clinical characteristics of patients.

\begin{tabular}{|c|c|}
\hline Characteristics & No. of patients \\
\hline \multicolumn{2}{|l|}{ UICC (TNM) stage } \\
\hline I & 7 \\
\hline II & 27 \\
\hline III & 25 \\
\hline IV & 8 \\
\hline \multicolumn{2}{|l|}{ Tumor (T) stage } \\
\hline pTis-1 & 2 \\
\hline pT2 & 17 \\
\hline pT3 & 43 \\
\hline pT4 & 5 \\
\hline \multicolumn{2}{|l|}{$\mathrm{N}$ stage } \\
\hline No & 33 \\
\hline N1 & 30 \\
\hline $\mathrm{N} 2$ & 4 \\
\hline \multicolumn{2}{|l|}{ M stage } \\
\hline M0 & 60 \\
\hline M1 & 7 \\
\hline \multicolumn{2}{|l|}{ Age } \\
\hline$<65$ & 30 \\
\hline $65-75$ & 20 \\
\hline $75-85$ & 16 \\
\hline$>85$ & 1 \\
\hline \multicolumn{2}{|l|}{ Sex } \\
\hline Male & 40 \\
\hline Female & 27 \\
\hline \multicolumn{2}{|l|}{ Tumor location } \\
\hline Right colon & 15 \\
\hline Left colon & 3 \\
\hline Transverse colon & 5 \\
\hline Sigmoid colon & 15 \\
\hline Rectum & 29 \\
\hline \multicolumn{2}{|l|}{ Histological grade } \\
\hline Well differentiated & 66 \\
\hline Poorly differentiated & 1 \\
\hline \multicolumn{2}{|l|}{ Mucinous Colloid Type } \\
\hline No & 53 \\
\hline Yes & 14 \\
\hline
\end{tabular}

Inc.) and hematoxylin staining were performed according to standard protocols. Slides were fixed via neutral gum for $\sim 1 \mathrm{~min}$ at room temperature and images were obtained using an Olympus IX71 inverted microscope with a DP2-BSW Olympus image acquisition software system (Olympus Corp.).

Cell line and reagents. The human CRC cell line HCT116 was purchased from the University of Colorado Cancer Center Cell Bank and cultured in RPMI-1640 medium supplemented with $10 \%$ FBS (Invitrogen; Thermo Fisher Scientific, Inc.) at $37^{\circ} \mathrm{C}$ in a $5 \% \mathrm{CO}_{2}$ atmosphere. Cells were digested and passaged when cell confluence reached $80 \%$. Recombinant human (rh) 
Table II. The primers of RT-qPCR.

\begin{tabular}{lll}
\hline Gene & \multicolumn{1}{c}{ Forward primer } & \multicolumn{1}{c}{ Reverse primer } \\
\hline Beclin1 & CAAGATCCTGGACCGTGTCA & TGGCACTTTCTGTGGACATCA \\
p62 & GACTACGACTTGTGTAGCGTC & AGTGTCCGTGTTTCACCTTCC \\
VSP34 & GGACCTTCTGACCACGAT & GCAACAGCATAACGCCTC \\
ATG7 & TGTATAACACCAACACACTCGA & GGCAGGATAGCAAAACCAATAG \\
ATG4b & AGAGCCCGTTTGGATACT & GTCGATGAATGCGTTGAG \\
Actin & GGGACCTGACTGACTACCTC & TCATACTCCTGCTTGCTGAT \\
E-cadherin & AGTCACTGACACCAACGATAAT & ATCGTTGTTCACTGGATTTGTG \\
Vimentin & AGTCCACTGAGTACCGGAGAC & CATTTCACGCATCTGGCGTTC \\
Snaill & AAGGATCTCCAGGCTCGAAAG & GCTTCGGATGTGCATCTTGA \\
N-cadherin & TGTATGTGGGCAAGATCCACT & CTCGTCGATCAGGAAGATGGT \\
\hline
\end{tabular}

IL-1 $\beta$ protein and IL-1RA protein were purchased from R\&D Systems, Inc. The working concentration was $100 \mathrm{nM}$.

Protein extraction and western blot analysis. Total protein was extracted from HCT116 cells using RIPA lysis buffer (Beyotime Institute of Biotechnology) with $1 \%$ phenylmethanesulfonyl fluoride (PMSF). Then, equal amounts $(20 \mu \mathrm{g})$ of protein determined by BCA protein assay kit (Thermo Fisher Scientific, Inc.) were separated using 10\% SDS-PAGE gels. The proteins were then transferred to PVDF membranes. The membranes were blocked with $5 \%$ non-fat milk for $1 \mathrm{~h}$ at room temperature and then incubated with primary antibodies at $4^{\circ} \mathrm{C}$ for $12 \mathrm{~h}$. The following antibodies were tested: Epithelial (E)-cadherin (cat. no. 20874), neural (N)-cadherin (cat. no. 22018), vimentin (cat. no. 10366) and zinc finger protein Snaill (snaill; cat. no. 13099) rabbit polyclonal antibodies (1:1,000; ProteinTech Group, Inc.); p62 (cat. no. ab109012) and LC3B (cat. no. ab192890) rabbit polyclonal antibodies (1:2,000; Abcam); IL-1RA rabbit polyclonal antibody (1:1,000; cat. no. AF-201; R\&D Systems, Inc.). $\beta$-actin rabbit polyclonal antibodies (1:4,000; cat. no. 60008; ProteinTech Group, Inc.) were used as loading controls for normalization. The secondary antibodies were anti-rabbit antibodies and conjugated to horseradish peroxidase $(1: 4,000$; cat. no. SA00001; ProteinTech, Inc.). The membranes were incubated with the secondary antibodies for approximately $1 \mathrm{~h}$ at room temperature. The bands were visualized with ECL reagents (Thermo Fisher Scientific, Inc.) and developed using the Omega Lum ${ }^{\mathrm{TM}} \mathrm{G}$ (Aplegen/Gel Company). ImageJ (version 2017; National Institutes of Health) was used for densitometry.

$R N A$ extraction and reverse transcription-quantitative $P C R$ $(R T-q P C R)$. Total RNA was extracted from HCT116 cells using TRIzol $^{\mathrm{TM}}$ reagent (Invitrogen; Thermo Fisher Scientific, Inc.). cDNA was obtained from total RNA using a PrimeScript ${ }^{\text {TM }}$ RT reagent kit (Takara Bio, Inc.). The expression of mRNA was assessed by RT-qPCR, which was carried out in triplicate using a SYBR Premix Ex Taq ${ }^{\mathrm{TM}}$ kit (Takara Bio, Inc.) and an ABI 7900HT Real-Time PCR system $\left(95^{\circ} \mathrm{C}\right.$ for $30 \mathrm{sec} ; 95^{\circ} \mathrm{C}$ for $3 \mathrm{sec}, 60^{\circ} \mathrm{C}$ for $30 \mathrm{sec}, 40$ cycles; Applied Biosystems; Thermo Fisher Scientific, Inc.). The primers used are presented in Table II. The comparative cycle threshold values method $\left(2^{-\Delta \Delta C q}\right)$ was used to analyze the final results (11).

Cell proliferation assay. For this assay, $5 \times 10^{3}$ HCT 116 cells were seeded into 96-well plates and incubated for the following time-points: 0, 24, 48 and $72 \mathrm{~h}$. Before determination, $10 \mu \mathrm{l}$ of Cell-Counting Kit-8 (CCK-8; Dojindo Molecular Technologies, Inc.) solution was added to each well of the plate, and the incubation was continued for $2 \mathrm{~h}$. Finally, the absorbance of each well was measured at a $450 \mathrm{~nm}$ wavelength.

Clone formation test. For this assay, 500 HCT 116 cells were seeded into each well of 6-well plates and incubated at $37^{\circ} \mathrm{C}$. Clone size was observed under an ZEISS Axiovert 40 inverted microscope (Carl Zeiss AG; magnification, x200) every day until the number of cells in most wells was more than 50 . The medium was then removed and cells were stained with $0.2 \%$ crystal violet for $30 \mathrm{~min}$. The cells were washed three times with PBS, then images were acquired and clones were counted. The ratio of clone formation was calculated following the equation: Ratio of clone formation $(\%)=$ clone number $/ 500 \times 100 \%$.

Flow cytometry. A total of $2 \times 10^{5}$ HCT 116 cells were harvested and washed with PBS 3 times. The samples were then resuspended in $100 \mu \mathrm{l}$ binding buffer and stained with $5 \mu \mathrm{l}$ of Annexin $\mathrm{V}$ and propidium iodide (PI) for $20 \mathrm{~min}$ at room temperature in the dark. Subsequent to staining, an additional $400 \mu \mathrm{l}$ binding buffer was added to the sample and resuspended. Analyses were performed with flow cytometry (BD Biosciences).

Cell migration and invasion assays. Cell migration and invasion were analyzed using Transwell plates (24-well insert; $8 \mu \mathrm{m}$ pore size; BD Biosciences). The filters (Corning, Inc.) were coated with Matrigel for invasion assays and uncoated for migration assays. A total of $55 \mu 1$ Matrigel suspended in PBS was used to coat the plates (1:8 dilution; BD Biosciences). For the migration assays, $5 \times 10^{4}$ HCT116 cells were suspended in $200 \mu \mathrm{l}$ of serum-free medium and seeded into the upper chambers of the Transwells. A 600- $\mu$ l volume of medium containing $10 \%$ FBS was then added to the lower chamber as a chemoattractant. After incubation at $37^{\circ} \mathrm{C}$ for $24 \mathrm{~h}$, the membranes were 


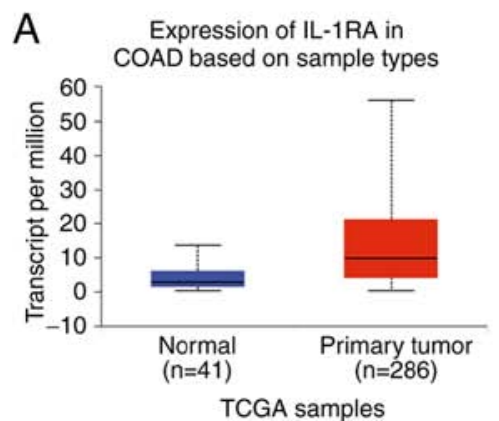

C

IL-1 $\beta$
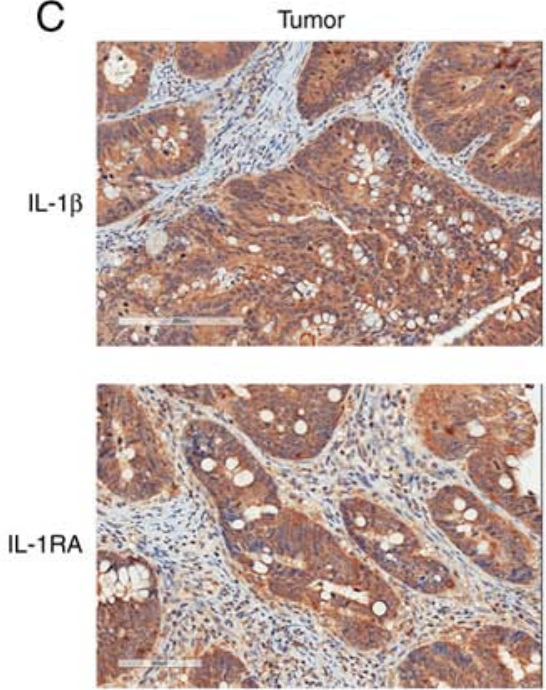
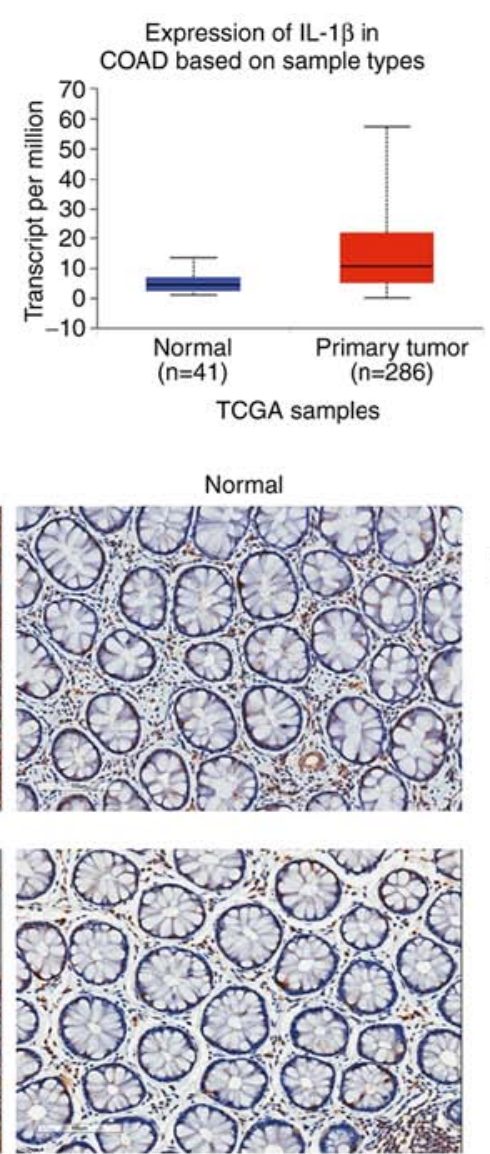

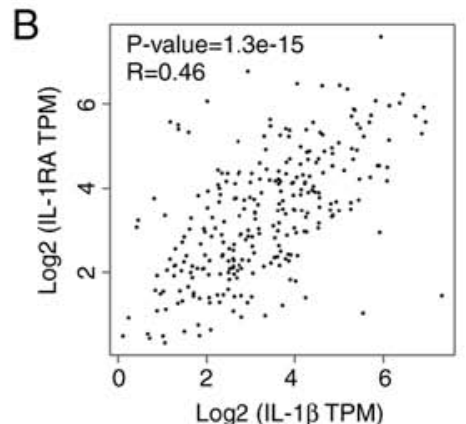

$D$

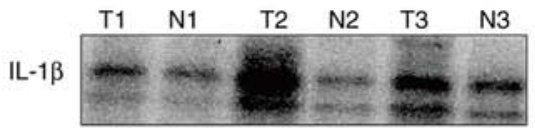

IL-1RA

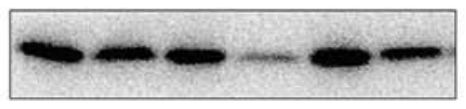

$\beta$-actin

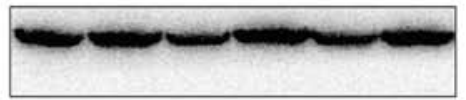

$\mathrm{E}$

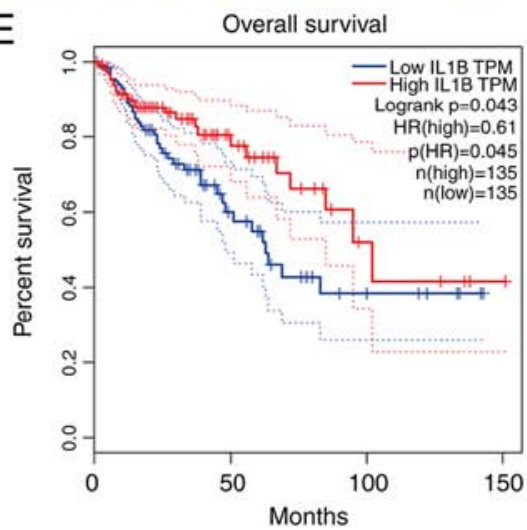

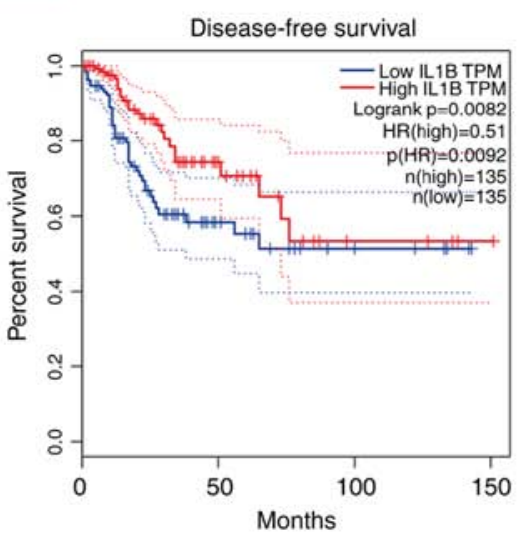

Figure 1. (A) mRNA expression of IL-1 $\beta$ and IL-1RA was analyzed by the UALCAN tool. (B) Co-expression between IL-1 $\beta$ and IL-1RA analyzed by the GEPIA tool. (C) Protein expression of IL-1 $\beta$ and IL-1RA confirmed by IHC. (D) Protein expression of IL-1 $\beta$ and IL-1RA confirmed by western blotting. (E) Association etween IL-1 $\beta$ and OS/RFS analyzed by the GEPIA tool. IL, interleukin; OS, overall survival; RFS, recurrence-free survival.

fixed with $4 \%$ formaldehyde for $30 \mathrm{~min}$ and stained with $0.1 \%$ crystal violet at room temperature for $30 \mathrm{~min}$. For invasion assays, $1 \times 10^{5}$ HCT116 cells suspended in $200 \mu \mathrm{l}$ serum-free medium were seeded into the Matrigel-coated upper chambers of the Transwells and the protocol followed was as aforementioned. The cells were counted and images were captured under an inverted microscope (magnification, x400) in 5 different fields of view per filter. Each condition was studied in triplicate.

Wound healing assay. For this assay, $5 \times 10^{5}$ HCT 116 cells were seeded into 6 -well plates and cultured at $37^{\circ} \mathrm{C}$ for 24 h. A $200-\mu 1$ sterile micro-pipette tip was used to scratch the confluent monolayers in a straight line when cells were
$80-90 \%$ confluent. Floating cells were then removed by washing with PBS three times and the cells were cultured in serum-free medium. Images of the same wound position were captured after at 0 and $48 \mathrm{~h}$ under a microscope. The migration results were analyzed using by ImageJ software (version 2017; National Institutes of Health).

Subcutaneous xenografts of nude mice. Balb/c-nude mice (age, 5 weeks) were provided by the Beijing Vital River Laboratory Animal Technology Co., Ltd. All detailed experimental procedures were approved by the Institutional Animal Care and Utilization Committee of Fudan University Pudong Animal Experimental Center. All the mice $(n=16)$ were randomly divided between the rhIL-1 $\beta$ group $(n=8)$ and the normal 

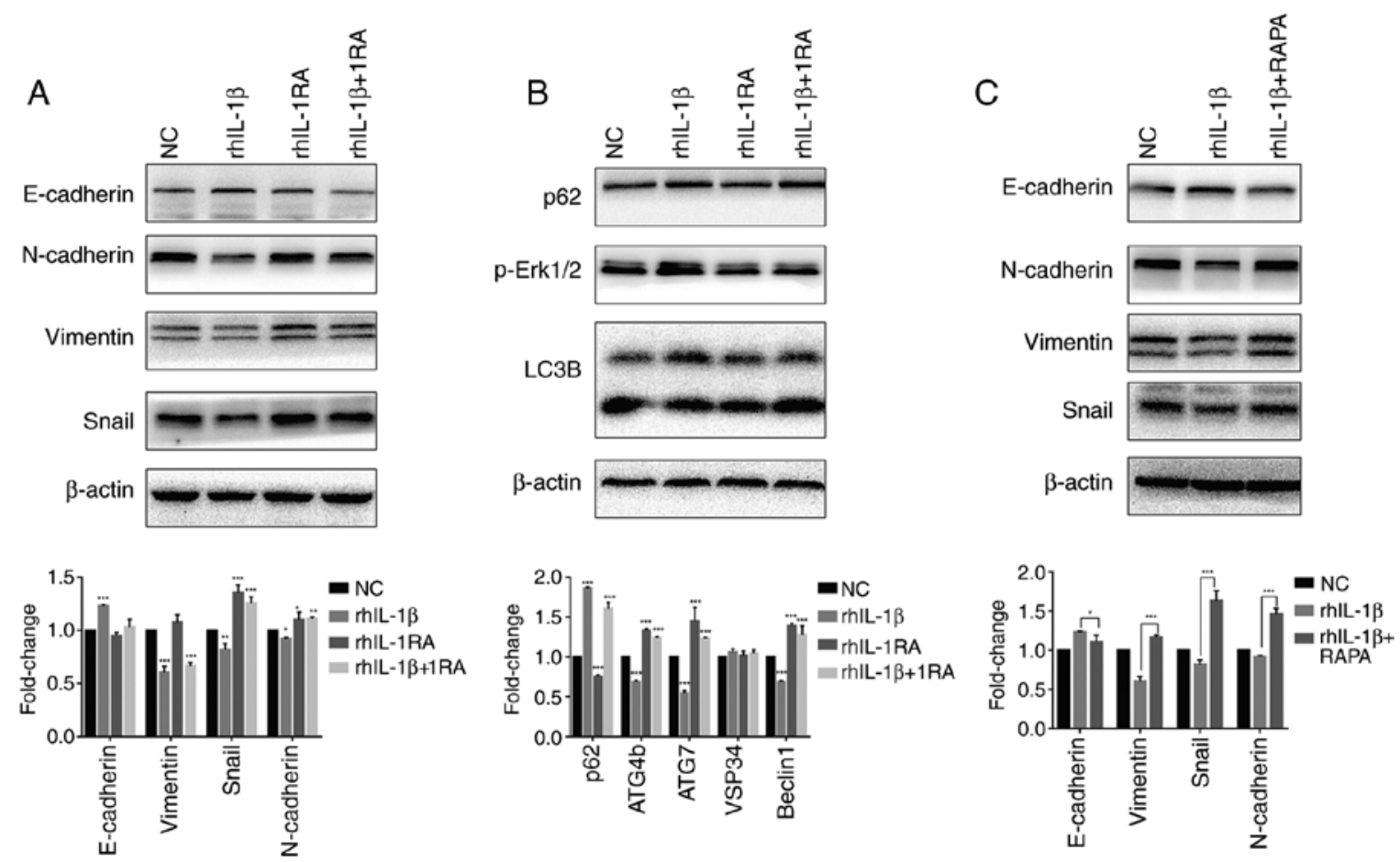

Figure 2. (A) EMT-associated markers detected by western blotting and RT-qPCR. (B) Autophagy-associated markers detected by western blotting and RT-qPCR. (C) EMT-associated markers detected by western blotting and RT-qPCR after treatment of RAPA in the rhIL- $1 \beta$ group. ${ }^{*} \mathrm{P}<0.05,{ }^{* * *} \mathrm{P}<0.01$ and ${ }^{* * * *} \mathrm{P}<0.001$. EMT, epithelial-mesenchymal transition; RT-qPCR, reverse transcription quantitative PCR; RAPA, rapamycin rh, recombinant human, IL, interleukin.

control (NC) group ( $\mathrm{n}=8)$. HCT-116 cells $\left(5 \times 10^{6}\right)$ suspended in $100 \mu$ l PBS were injected subcutaneously from the axilla of each nude mouse. After 2 weeks, the rhIL-1 $\beta$ group were treated with $1 \mu \mathrm{g}$ rhIL-1 $1 \beta$ dissolved in $100 \mu \mathrm{l}$ normal saline via intraperitoneal injection (once every two days, for 14 days); while, the NC group was treated with $100 \mu 1$ normal saline as a placebo. The long (L) and short (S) diameter of the tumors were measured with a Vernier caliper every 3 days (tumor volume $=\mathrm{LxS}^{2} / 2$ ). The growth curve of subcutaneous tumors was plotted based on the measured tumor volume. All mice were euthanized 2 weeks after treatment by injection of excessive $2 \%$ sodium pentobarbital, followed with rapid cervical vertebra dislocation.

Statistical analysis. SPSS software (version 19.0, IBM Corp.) was used for statistical analysis of all experimental data. GraphPad Prism (version 7; GraphPad Software, Inc.) was used to determine the statistical results. All data are expressed as the mean \pm standard deviation. Statistical analysis of data from 2 groups was performed using a t-test. The comparison between multiple groups was performed using one-way ANOVA and then an LSD test. $\mathrm{P}<0.05$ was considered to indicate a statistically significant difference.

\section{Results}

$I L-1 \beta$ and IL-1RA are upregulated in CRC and are associated with an increased rate of overall survival (OS). The expression of IL- $1 \beta$ and IL-1RA in CRC were analyzed by UALCAN web tools based on the TCGA database, and significantly higher levels of both IL-1 $\beta$ and IL-1RA were observed in CRC tumor tissue compared with normal mucosa (9) (http://ualcan.path. uab.edu/; Fig. 1A). Significant co-expression between IL-1 $\beta$ and IL-1RA genes was identified via GEPIA web tools based on TCGA database (10) (http://gepia.cancer-pku.cn/; Fig. 1B). Additionally, western blotting (Fig. 1C) and IHC (Fig. 1D) were performed to determine the protein expression levels, and the results indicated that both IL-1 $\beta$ and IL-1RA were increased in CRC compared with paired non-tumor mucosa. Collectively, these data indicated increased expression of IL-1 $\beta$ and IL-1RA in tumor tissues at both the mRNA and protein levels. To explore the clinical significance of increased IL-1 $\beta$ expression in CRC, the GEPIA tool was used to analyze OS and recurrence-free survival (RFS) rates in CRC patients based on the TCGA database. Increased expression of IL-1 $\beta$ was associated with an increased rate of OS and RFS (Fig. 1E)

The IL-1 $\beta / I L I R A$ axis regulates EMT via autophagy in vitro. Western blotting and RT-qPCR were performed to determine the expression levels of several EMT-associated markers (Fig. 2A). rhIL-1 $\beta$ increased the expression of E-cadherin, whereas it reduced the expression of $\mathrm{N}$-cadherin, vimentin and Snail. rhIL-1RA revealed the opposite effect in EMT markers compared with rhIL-1 $\beta$; while, rhIL-1RA rescued the increased expression of E-cadherin and reduced expression of $\mathrm{N}$-cadherin, vimentin and Snail in the rhIL-1 $\beta$-treated group. These results indicated that rhIL-1 $\beta$ inhibited EMT whereas rhIL-1RA induced EMT in HCT-116 cells. The levels of several key autophagy-associated markers in each group were also determined (Fig. 2B). rhIL-1 $\beta$ increased the expression of p62 and decreased the ratio of LC3 II/I, expression of cysteine protease ATG4b (ATG4b), ubiquitin-like modifier-activating enzyme 
A

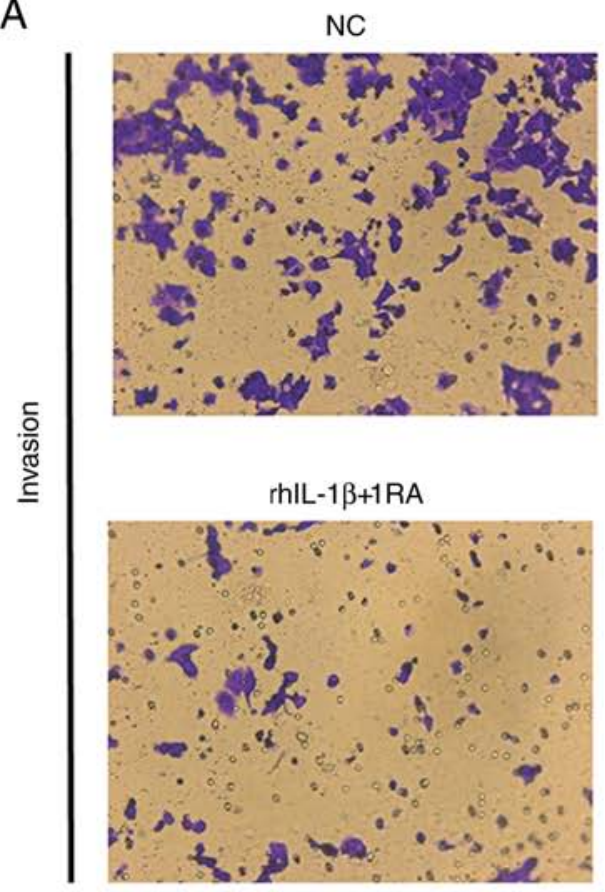

B

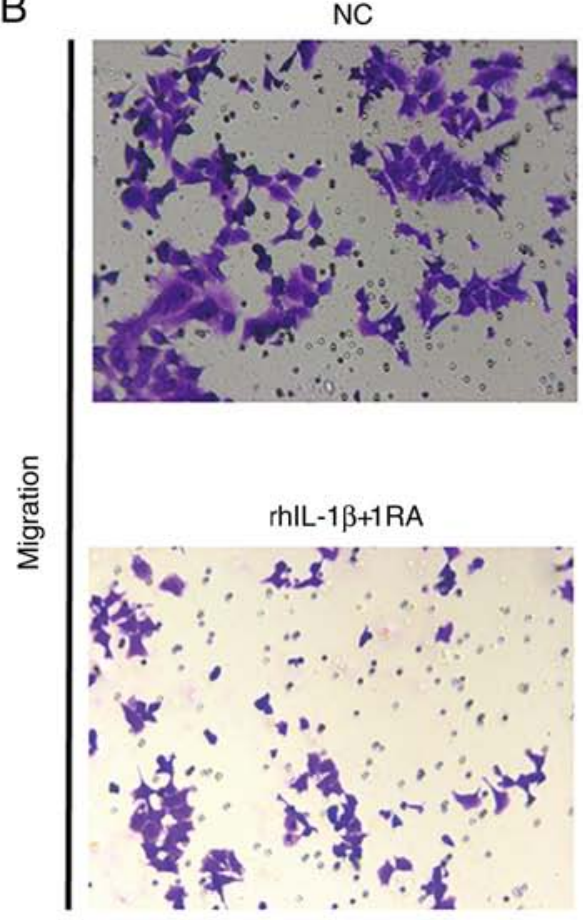

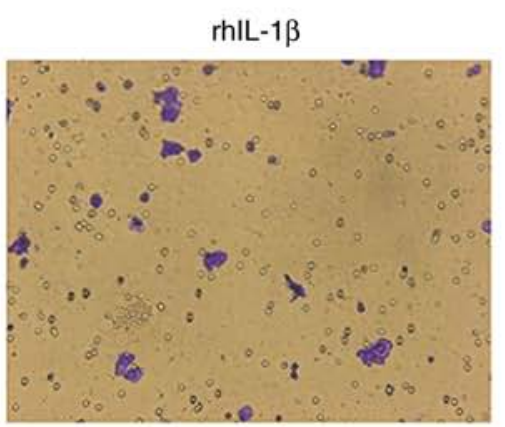
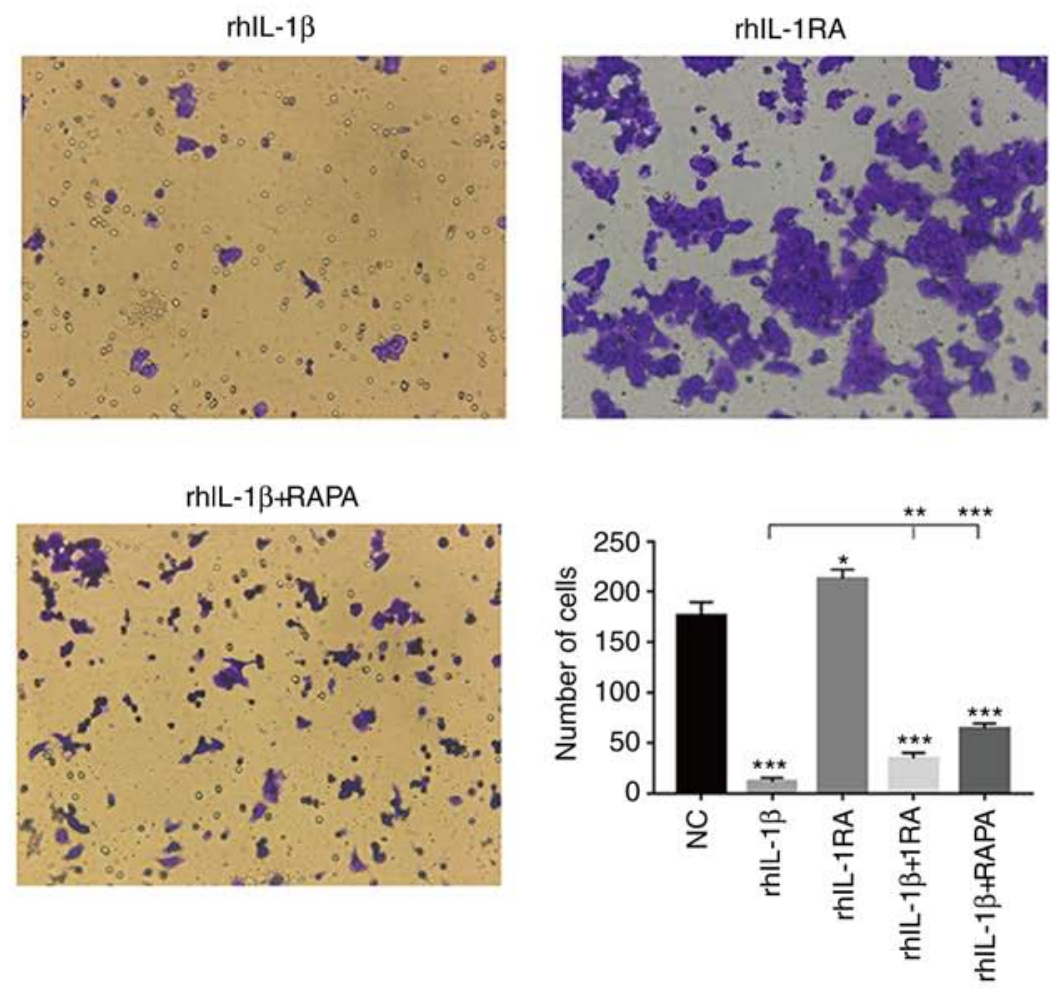

rhIL-1 $1 \beta$
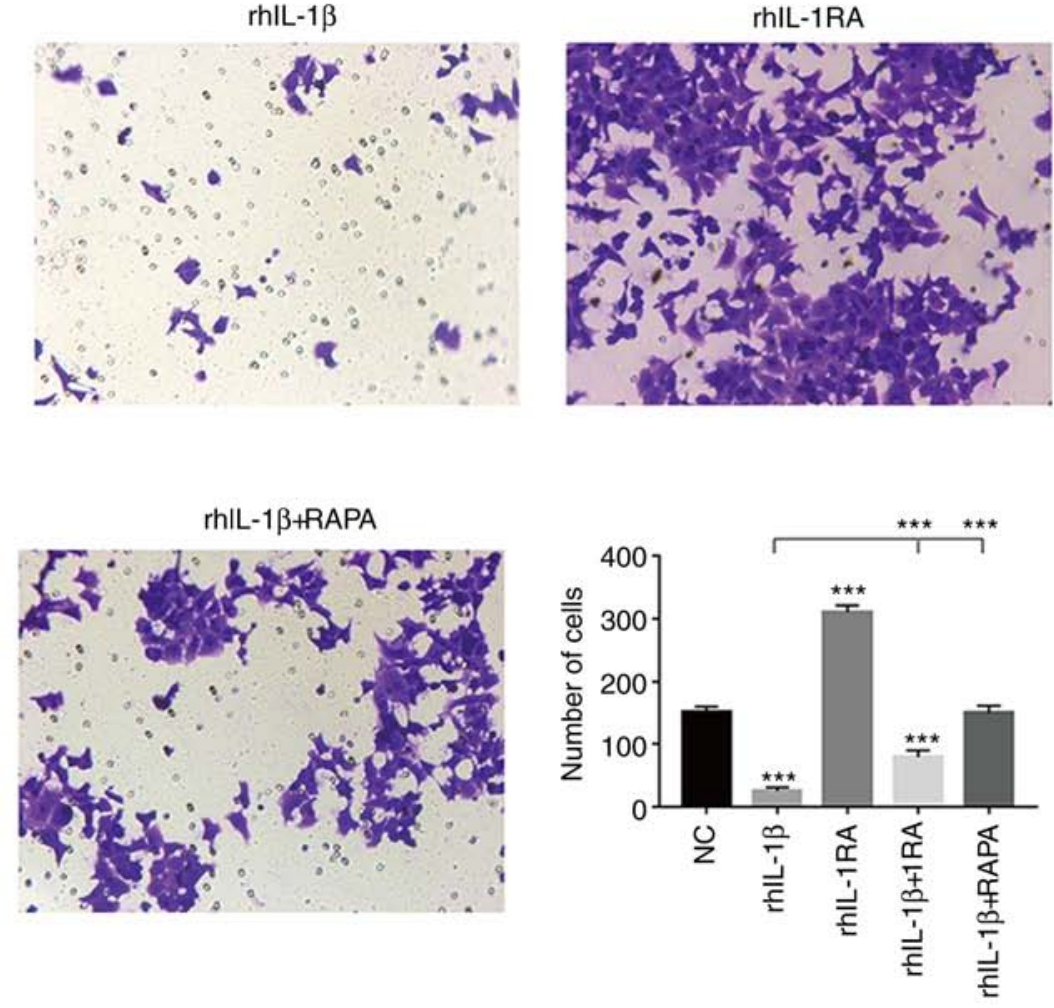

Figure 3. (A) Invasion ability of each group analyzed by Transwell assay. (B) Migration ability of each group analyzed by Transwell assay. ${ }^{*} \mathrm{P}<0.05,{ }^{* *} \mathrm{P}<0.01$ and ${ }^{* * * *} \mathrm{P}<0.001$. rh, recombinant human, IL, interleukin; RAPA, rapamycin.

ATG7 (ATG7) and Beclin1. rhIL-1RA revealed the opposite effect on autophagy markers when compared with rhIL-1 $\beta$; while, rhIL-1RA rescued the increased expression of p62 and reduced ratio of LC3 II/I, expression of ATG4b, ATG7, VSP34 and beclin1. These results indicated that rhIL-1 $\beta$ inhibited autophagy whereas rhIL-1RA induced autophagy in HCT-116 cells. To study the association between rhIL-1 $/$ /RA-regulated autophagy and EMT, autophagy activator RAPA ( $5 \mathrm{mM}$ for $48 \mathrm{~h}$ ) was used to treat the rhIL-1 $\beta$ group. It was revealed that RAPA significantly rescued increased expression of E-cadherin and reduced expression of $\mathrm{N}$-cadherin, vimentin and Snail in the rhIL-1 $\beta$ group compared with levels in mice untreated with RAPA. These results indicated that IL-1//IL-1RA regulated EMT via autophagy. 
C

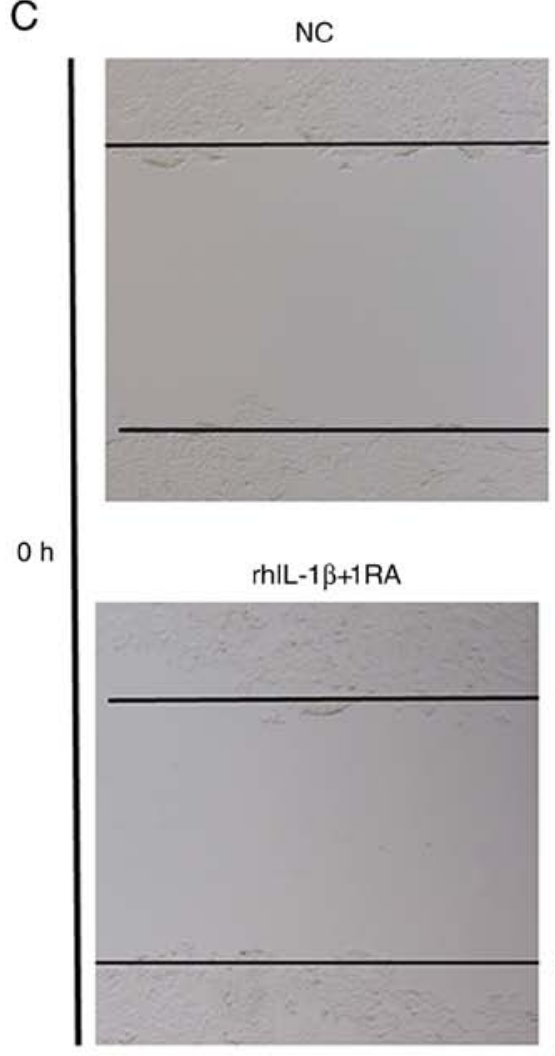

NC

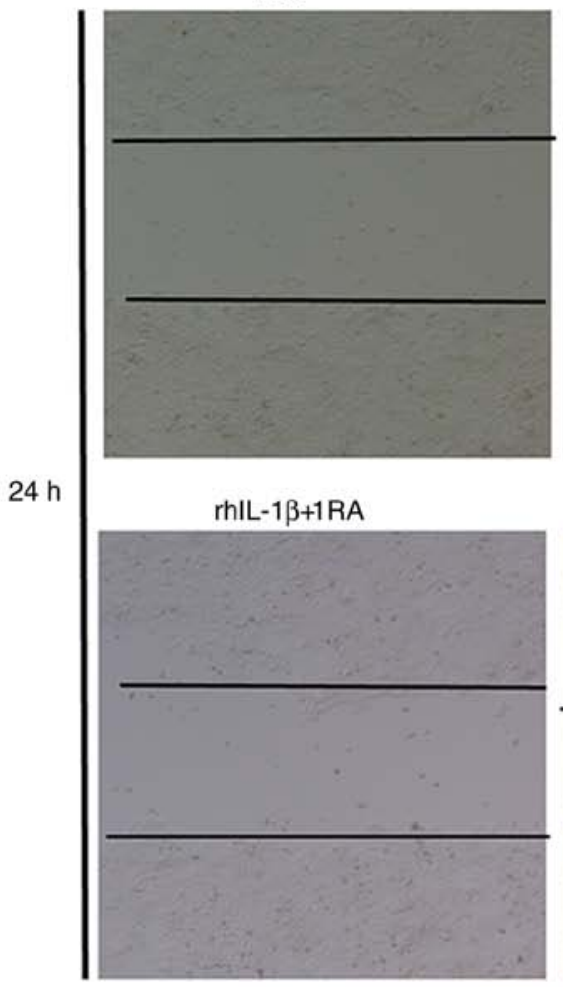

rhlL-1 $\beta$

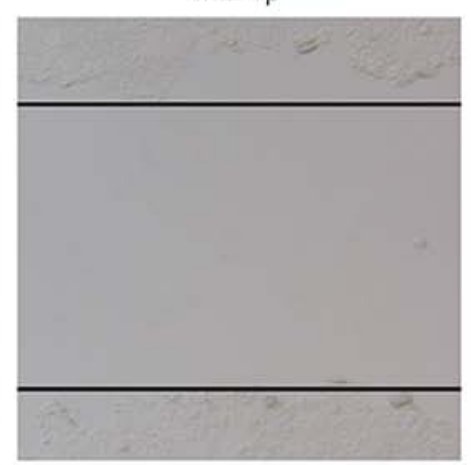

rhIL-1 $\beta+$ RAPA

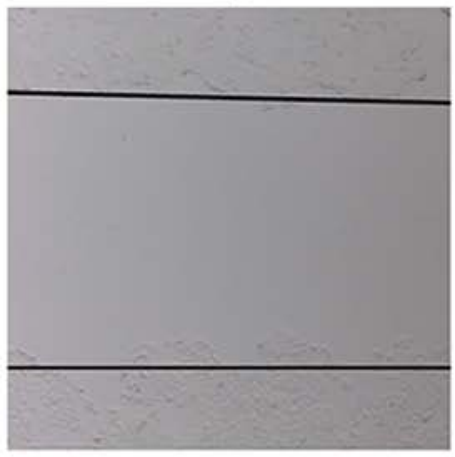

rhlL-1 $\beta$

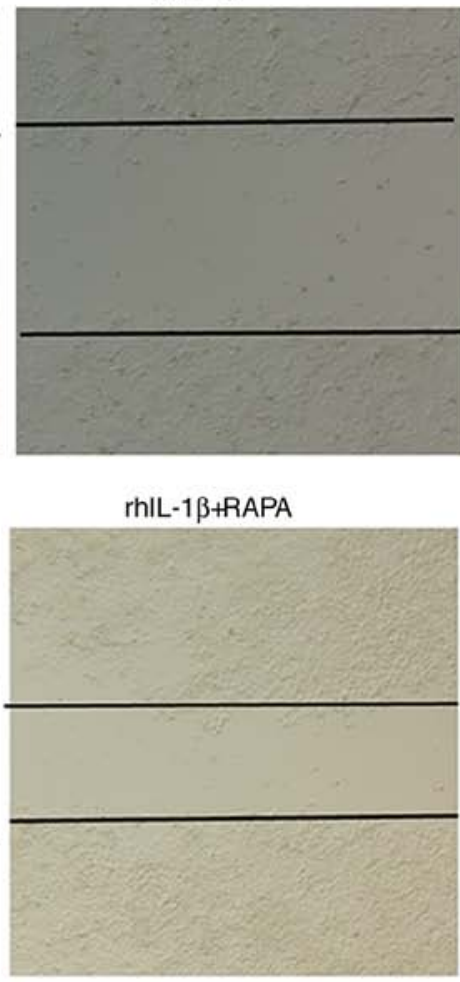

rhIL-1RA

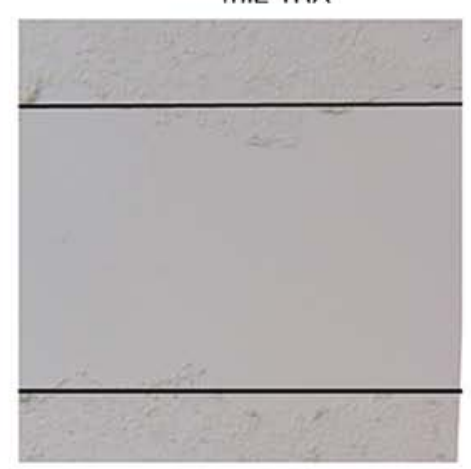

rhIL-1RA
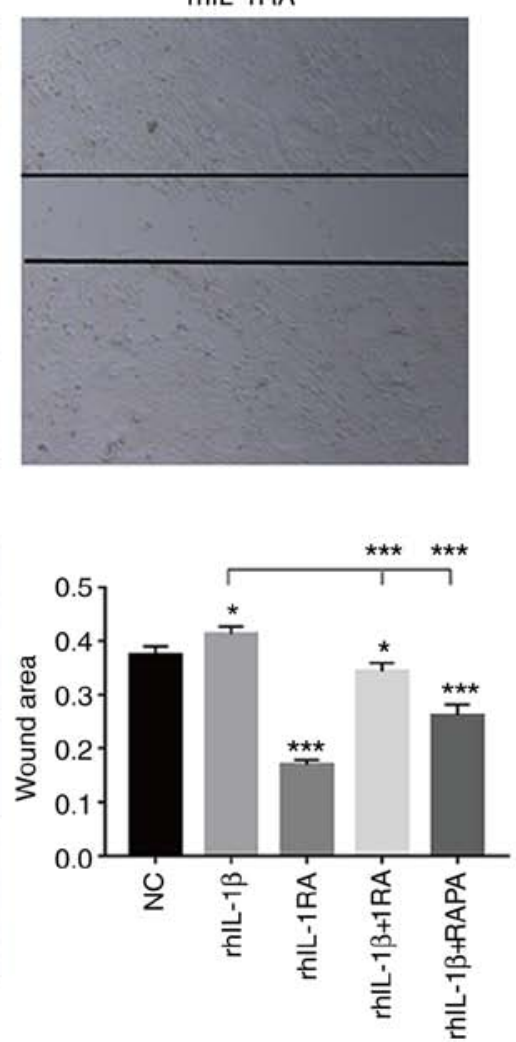

Figure 3. Continued. (C) Migration ability of each group analyzed by wound healing assay. ${ }^{*} \mathrm{P}<0.05,{ }^{* * *} \mathrm{P}<0.01$ and ${ }^{* * * *} \mathrm{P}<0.001$. rh, recombinant human, IL, interleukin; RAPA, rapamycin.

$I L-1 \beta$ inhibits cell migration and invasion. Transwell assays were performed to assess the impact of IL-1 $\beta$ and IL-1RA on cell invasion and migration. In the invasion assay, rhIL-1 $\beta$ treatment decreased the invasion ability of HCT-116 cells, whereas rhIL-1RA increased the invasion ability compared with the NC group. Both rhIL-1RA and RAPA could rescue this invasion ability in the rhIL-1 $\beta$ group (Fig. 3A). Migration assays exhibited similar results to the invasion assay (Fig. 3B). 
A
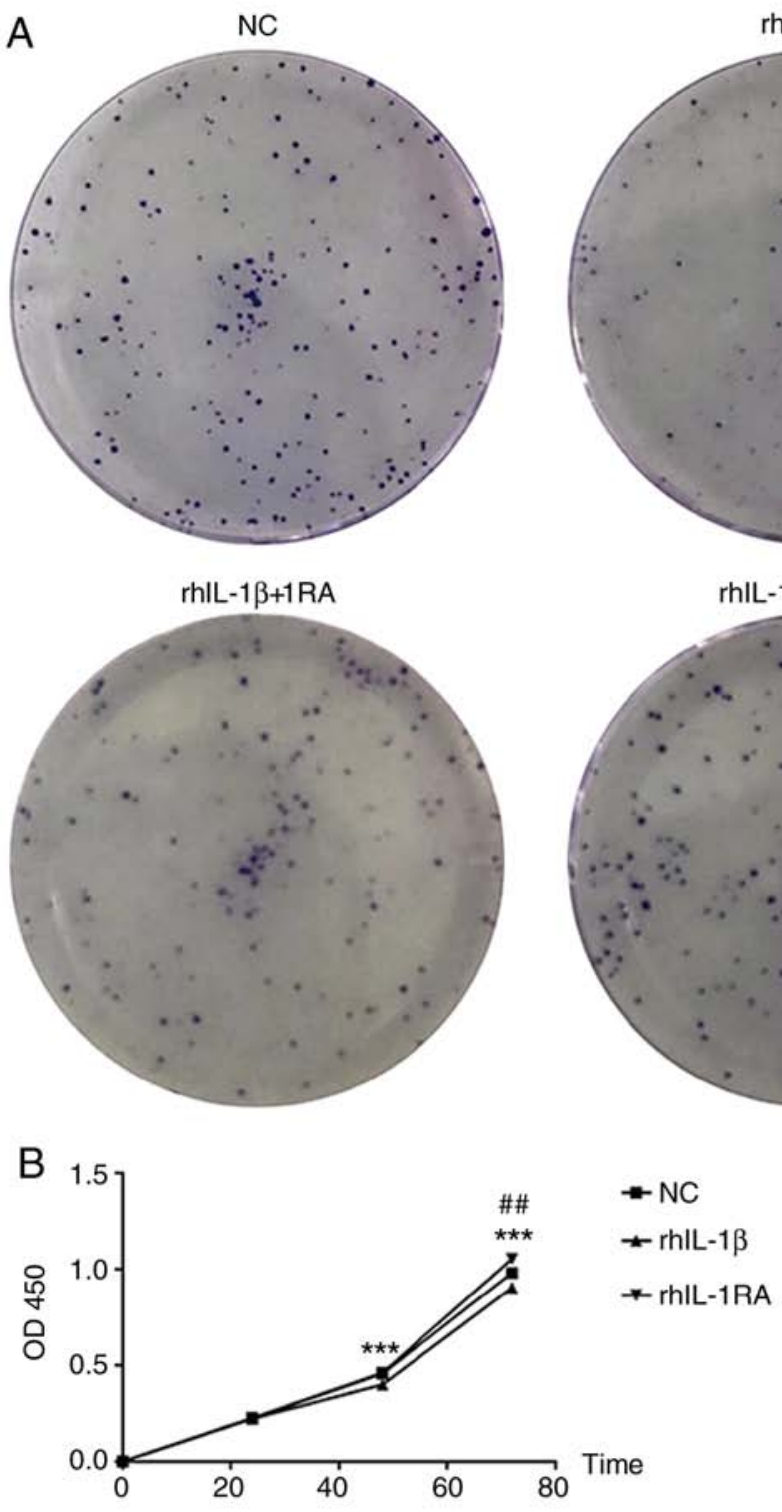
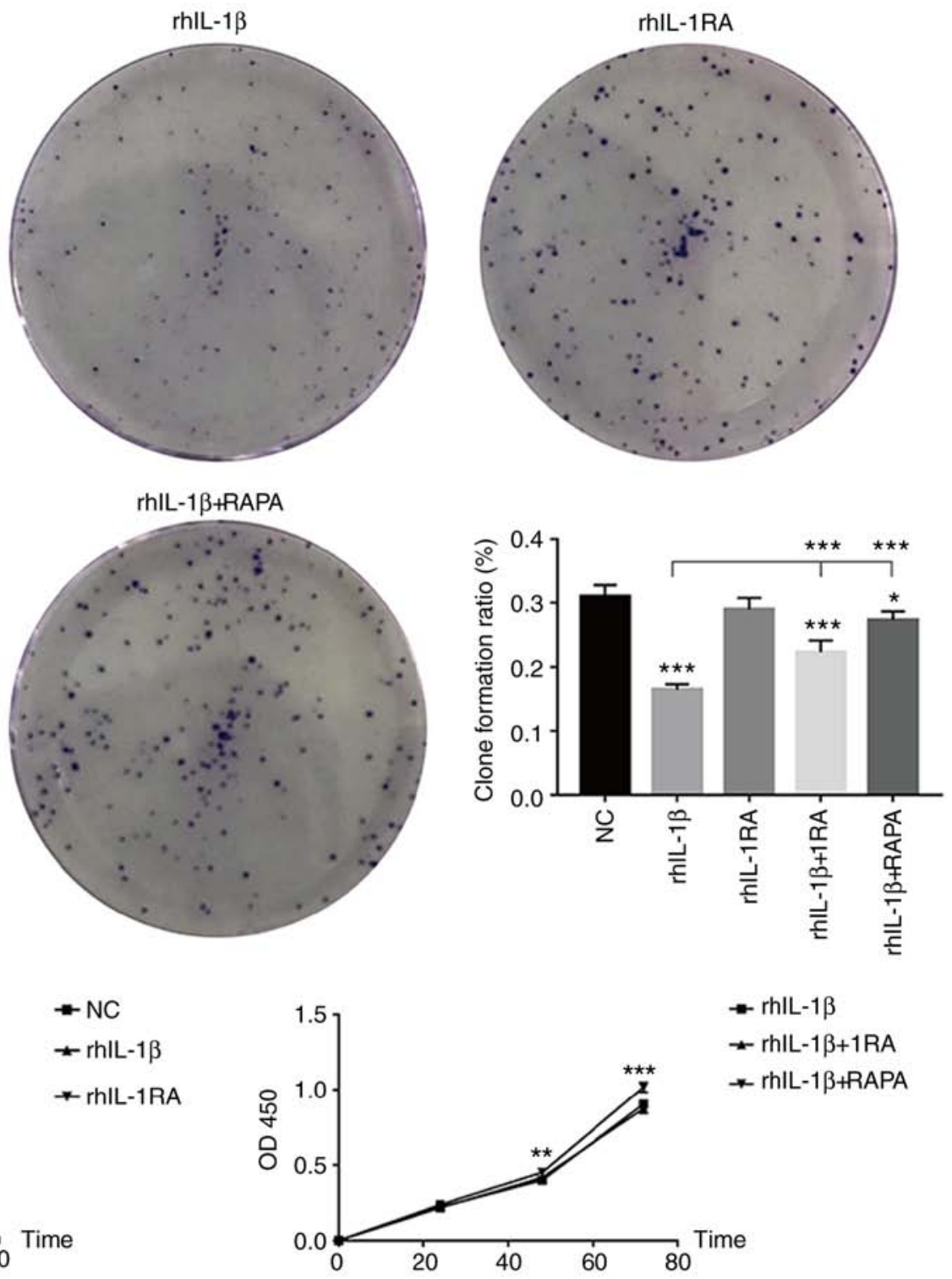

Figure 4. (A) Clone formation ability of each group. ${ }^{*} \mathrm{P}<0.05$ and ${ }^{* * *} \mathrm{P}<0.001$. (B) Proliferation of each group detected by $\mathrm{CCK}-8$ assay. rh1L- $\beta$ vs. NC, ${ }^{* *} \mathrm{P}<0.01$ and ${ }^{* * *} \mathrm{P}<0.001$; rhIL-1RA vs. NC, ${ }^{\# \#} \mathrm{P}<0.01$. (C) Cell apoptosis of each group detected by flow cytometry $\left.{ }^{* * *} \mathrm{P}<0.001\right)$. rh, recombinant human, IL, interleukin; RAPA, rapamycin.

Furthermore, the migratory ability of each group was also confirmed by wound healing assay. rhIL-1 $\beta$ increased the wound area in HCT-116 cells compared with the control cells, whereas rhIL-1RA decreased it. Both rhIL-1RA and RAPA treatment decreased the wound area in the rhIL-1 $\beta$ group compared with control treatments (Fig. 3C).

$I L-1 \beta$ reduces cell proliferation and clone formation ability and promotes cell apoptosis. Clone formation assays and a CCK-8 assay were performed to assess clone formation ability and proliferation in each group. rhIL- $1 \beta$ reduced clone formation in HCT-116 cells compared to untreated cells, whereas rhIL-1RA treatment exhibited no effect. In addition, both rhIL-1RA and RAPA could rescue inhibited clone formation in the rhIL-1 $\beta$-treated group (Fig. $4 \mathrm{~A}$ ). Furthermore, rhIL-1 $\beta$ inhibited proliferation of HCT-116 at $48 \mathrm{~h}$ and $72 \mathrm{~h}$ compared with the control treatment; whereas rhIL-1RA promoted proliferation of HCT-116 cells at $72 \mathrm{~h}$ compared with the control treatment. RAPA could rescue inhibited proliferation in the rhIL-1 $\beta$ group, whereas rhIL-1RA exhibited no effect (Fig. 4B). Flow cytometry was performed to assess cell apoptosis in each group. rhIL-1 $\beta$ treatment $(51.97 \pm 1.73 \%)$ promoted apoptosis of HCT-116 cells compared with the control treatment $(27.19 \pm 0.33 \%)$, whereas rhIL-1RA exhibited no effect $(25.56 \pm 0.09 \%)$. In addition, both rhIL-1RA $(28.3 \pm 0.24 \%)$ and RAPA $(27.09 \pm 0.24 \%)$ could rescue the increase in apoptosis observed in the rhIL-1 $\beta$ group (Fig. 4C).

$I L-1 \beta$ inhibits growth of subcutaneous xenografts in nude mice. To demonstrate the effect of rhIL-1 $\beta$ in vivo, subcutaneous xenografts were injected into nude mice. A total of $1 \mu \mathrm{g}$ rhIL-1 $\beta$ was administered intraperitoneally (once per two days) and the results revealed that it significantly inhibited the growth of xenografts between day 5 and 15 (Fig. 5A and B). In addition, rhIL-1 $\beta$ exhibited no effect on mouse weight, health, food intake, sleep and activity compared with control treatment (Fig. 5C). 
C
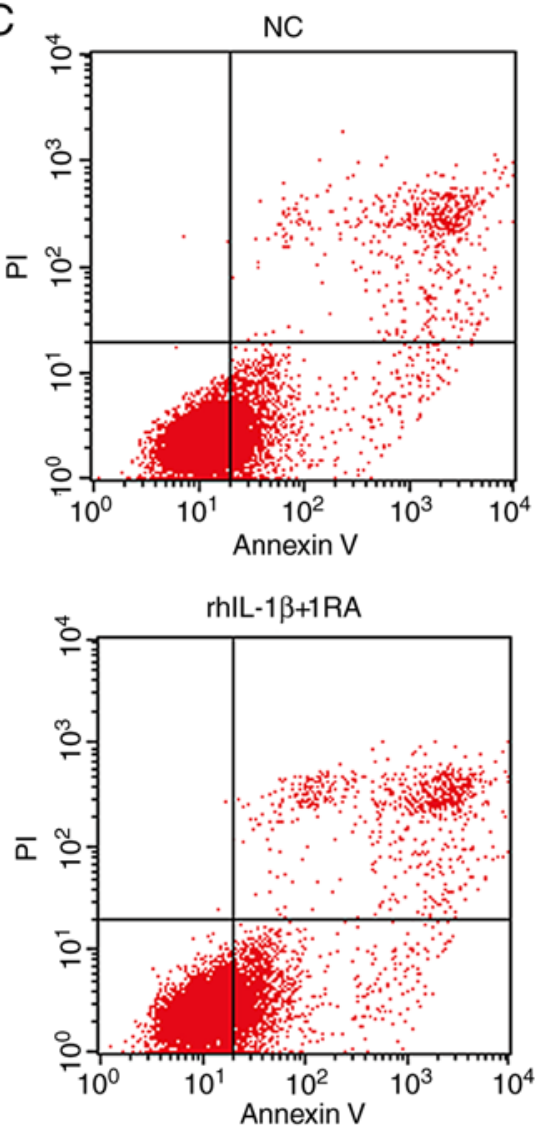
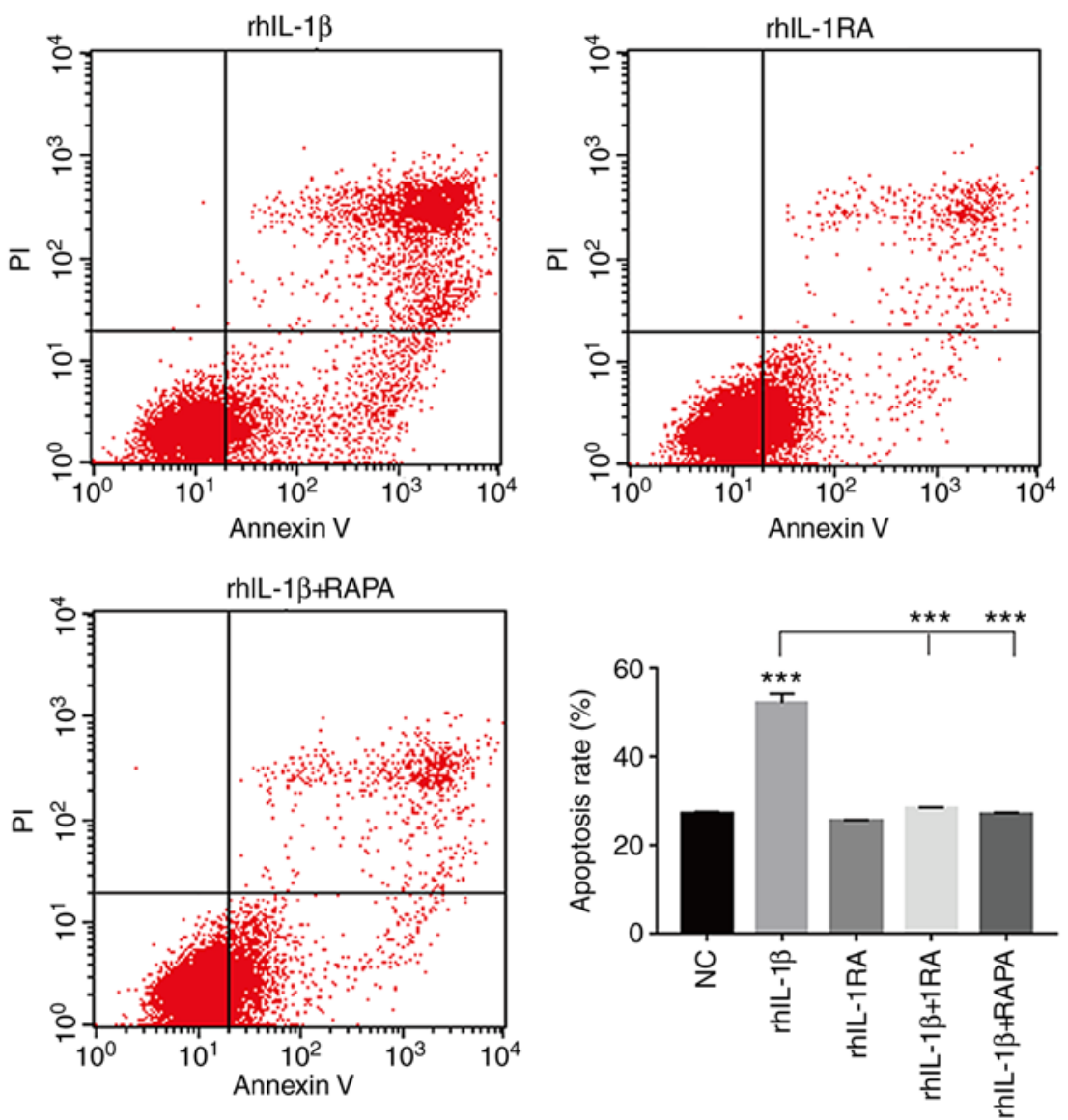

Figure 4. Continued. (C) Cell apoptosis of each group detected by flow cytometry ( $\left.{ }^{* * *} \mathrm{P}<0.001\right)$. rh, recombinant human, IL, interleukin; RAPA, rapamycin

\section{Discussion}

The tumor microenvironment is the area between tumor cells and adjacent normal tissues. Its components include extracellular matrix, soluble molecules and tumor stromal cells. Once the tumor microenvironment is formed, numerous immune cells, such as $\mathrm{T}$ cells, macrophages are chemotactically drawn to this point (12). In addition to cellular factors, the molecules in the tumor microenvironment include extracellular matrix molecules, cytokines and chemokines. Cells and molecules in the tumor microenvironment are dynamic, reflecting the essence of tumor microenvironment evolution, and the final outcome is that a large number of immunosuppressive cells such as myeloid-derived suppressor cells aggregate in the tumor microenvironment to regulate immune escape, growth and metastasis of the tumor (13).

In the present study expression of IL-1 $\beta$ was assessed in CRC patients and a significant increase was observed when compared with normal tissues. In previous research of other tumors, IL-1 $\beta$ was associated with metastasis and induction of EMT (7). It was hypothesized that IL-1 $\beta$ would play a tumorigenic role in CRC. However, analysis found higher expression of IL-1 $\beta$ was associated with better OS and RFS, indicating a beneficial role in CRC. Significant co-expression between IL-1 $\beta$ and IL-1RA was also observed, indicating a possible interaction between them.

The regulation of EMT by rhIL-1 $\beta$ was studied as was demonstrated to have an activation effect in breast cancer (6).
Notably, $100 \mathrm{nM}$ rhIL-1 $\beta$ for $48 \mathrm{~h}$ significantly inhibited EMT, in contrast with the results of a previous study in breast cancer. In addition, rhIL-1RA induced EMT and rescued inhibition of EMT by rhIL-1 $\beta$. Autophagy is one of the main regulatory mechanisms of EMT. Long non-coding RNA CPS1-IT may suppress metastasis and EMT by inhibiting hypoxia-induced autophagy through inactivation of hypoxia inducible factor-1 $\alpha$ in CRC (14). In the present study levels of several key markers of autophagy were determined, and the results indicated that rhIL-1 $\beta$ inhibited autophagy in CRC, whereas rhIL-1RA activated autophagy. Furthermore, autophagy activator RAPA significantly rescued inhibited autophagy in the rhIL-1 $\beta$ group. Collectively, these results indicated that IL-1 $\beta$ inhibited EMT in vitro via inhibition of autophagy; while, IL-1RA induced EMT in vitro via activation of autophagy. EMT is an important process for tumors to acquire invasiveness, and autophagy had also been demonstrated to promote invasion and metastasis $(15,16)$. Autophagy is a process of phagocytosis of cytoplasmic proteins or organelles into vesicles and fusion with lysosomes to form autophagic lysosomes, which degrade the contents of the lysosomes, thereby realizing the metabolic needs of the cells themselves and leading to the renewal of some organelles. Many malignant tumors are positively or negatively correlated with autophagy in many stages of occurrence, development and metastasis $(17,18)$.

Transwell assays and wound healing assay were performed to assess cell invasion and migration. As anticipated, rhIL-1 $\beta$ significantly decreased cell invasion and migration and 

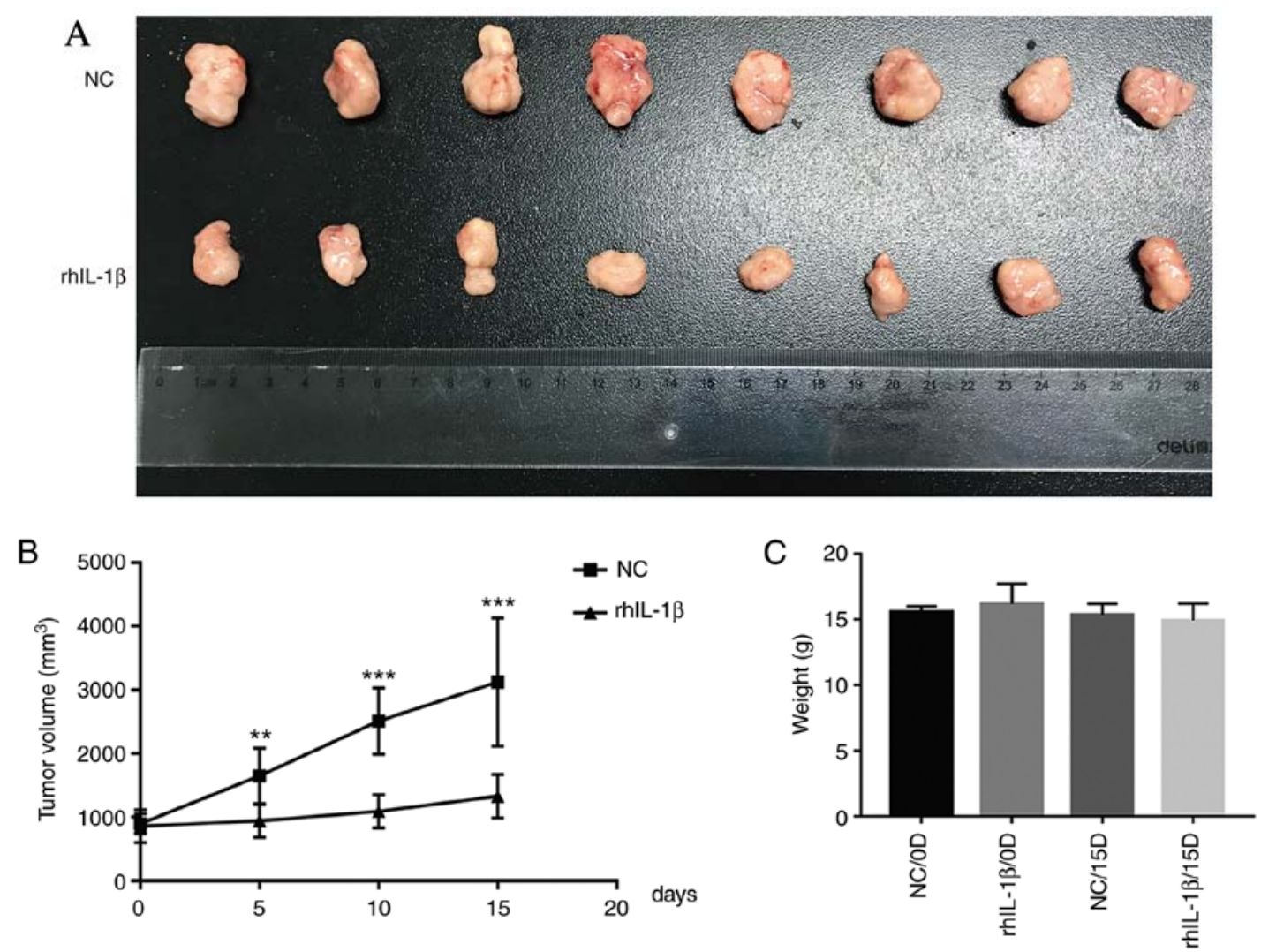

Figure 5. (A) Images of the subcutaneous xenografts. (B) Growth curve of xenografts in rhIL-1 $\beta$ and control groups. (C) Weight of the rhIL-1 $\beta$ and control groups before and after treatment. ${ }^{* *} \mathrm{P}<0.01,{ }^{* * *} \mathrm{P}<0.001$. rh, recombinant human; IL, interleukin.

rhIL-1RA promoted invasion and migration. In addition, both rhIL-1RA and RAPA exhibited a similar rescue effect of inhibited invasion and migration abilities in the rhIL-1 $\beta$ treated group. These data indicated that the IL-1 $\beta / 1 \mathrm{RA}$ axis regulated EMT via autophagy. In addition, rhIL-1 $\beta$ decreased clone formation ability in comparison with the control treatment, whereas rhIL-1RA exhibited no effect. In addition, both rhIL-1RA and RAPA could rescue inhibited clone formation ability in the rhIL-1 $\beta$ group. Furthermore, rhIL-1 $\beta$ inhibited proliferation of HCT-116 cells after $48 \mathrm{~h}$, whereas rhIL-1RA promoted proliferation of HCT-116 cells after $72 \mathrm{~h}$. RAPA could rescue inhibited proliferation in the rhIL-1 $\beta$ group, whereas rhIL-1RA exhibited no effect. In addition, rhIL-1 $\beta$ promoted apoptosis of HCT-116 cells, whereas rhIL-1RA exhibited no effect. Both rhIL-1RA and RAPA could rescue the increase of apoptosis in rhIL- $1 \beta$ group. These results indicated IL-1 $\beta-1$ RA autophagy-regulated clone formation, cell proliferation and apoptosis may be a complex process.

Finally, the therapeutic effect of rhIL-1 $\beta$ was assessed in vivo. rhIL-1 $\beta$ treatment significantly inhibited the growth of xenografts between 5 and 15 days compared with the control treatment, with no effect on general health status.

A limitation of the present study was that our research was performed only in HCT-116 cells, and more CRC cell lines remain to be investigated. We will further investigate the specific mechanism of the IL-1 $\beta$-1RA-autophagy axis in more CRC cell lines as well as other tumors.

In conclusion, IL-1 $\beta$ and IL-1RA were highly expressed in CRC patients. The IL-1 $\beta / 1 \mathrm{RA}$ axis was revealed to regulate
EMT, cell invasion, migration, clone formation, proliferation and apoptosis in vitro via autophagy. In addition, IL-1 $\beta$ also inhibited the growth of xenografts in vivo, and may be suitable as a new therapeutic drug for CRC patients.

\section{Acknowledgements}

Not applicable.

\section{Funding}

The present study was funded by Puxiu Medical Talents Training Program of Pudong Hospital (grant no. PX201702).

\section{Availability of data and materials}

The datasets used and analyzed during the current study are available from the corresponding author on reasonable request.

\section{Authors' contributions}

YC and ZY contributed equally to the cell experiments and mice model. BD and DW contributed to the statistical analysis of the data and collection of specimens. YQ and ZM contributed to the design of the study and supervision. All authors read and approved the final version of the manuscript. All authors read and approved the manuscript and agree to be accountable for all aspects of the research in ensuring that the accuracy or integrity of any part of the work are appropriately investigated and resolved. 


\section{Ethics approval and consent to participate}

All procedures involving human participants were performed in accordance with Shanghai Pudong Hospital Ethics Committee and with the 1964 Declaration of Helsinki and its later amendments or comparable ethical standards. All patients provided their written informed consent. The study protocol was approved by the Pudong Hospital Committee on human research. All detailed experimental animal procedures were approved by the Institutional Animal Care and Utilization Committee of Fudan University Pudong Animal Experimental Center.

\section{Patient consent for publication}

Not applicable.

\section{Competing interests}

The authors declare that they have no competing interests.

\section{References}

1. Taniguchi K and Karin M: IL-6 and related cytokines as the critical lynchpins between inflammation and cancer. Semin Immunol 26: 54-74, 2014.

2. Long AG, Lundsmith ET and Hamilton KE: Inflammation and colorectal cancer. Curr Colorectal Cancer Rep 13: 341-351, 2017

3. Huang C, Yang G, Jiang T, Zhu G, Li H and Qiu Z: The effects and mechanisms of blockage of STAT3 signaling pathway on IL-6 inducing EMT in human pancreatic cancer cells in vitro. Neoplasma 58: 396-405, 2011.

4. Lee S and Margolin K: Cytokines in Cancer immunotherapy. Cancers (Basel) 3: 3856-3893, 2011.

5. Masters SL, Dunne A, Subramanian SL, Hull RL, Tannahill GM, Sharp FA, Becker C, Franchi L, Yoshihara E, Chen Z, et al: Activation of the NLRP3 inflammasome by islet amyloid polypeptide provides a mechanism for enhanced IL-1 $\beta$ in type 2 diabetes. Nat Immunol 11: 897-904, 2010.

6. Soria G, Ofrishahak M, Haas I, Yaal-Hahoshen N, Leider-Trejo L, Leibovich-Rivkin T, Weitzenfeld P, Meshel T, Shabtai E, Gutman $\mathrm{M}$ and Ben-Baruch A: Inflammatory mediators in breast cancer: Coordinated expression of TNF $\alpha$ and IL-1 $\beta$ with CCL2 and CCL5 and effects on epithelial-to-mesenchymal transition. BMC Cancer 11: 130, 2011.
7. Huang Q, Lan F, Wang X, Yu Y, Ouyang X, Zheng F, Han J, Lin Y, Xie Y, Xie F, et al: IL-1 $\beta$-induced activation of p38 promotes metastasis in gastric adenocarcinoma via upregulation of AP-1/c-fos, MMP2 and MMP9. Mol Cancer 13: 18, 2014

8. Ito $\mathrm{H}$ and Miki C: Profile of circulating levels of interleukin-1 receptor antagonist and interleukin- 6 in colorectal cancer patients. Scand J Gastroenterol 34: 1139-1143, 1999.

9. Chandrashekar DS, Bashel B, Balasubramanya SAH, Creighton CJ, Ponce-Rodriguez I, Chakravarthi BVSK and Varambally S: UALCAN: A portal for facilitating tumor subgroup gene expression and survival analyses. Neoplasia 19: 649-658, 2017.

10. Tang Z, Li C, Kang B, Gao G, Li C and Zhang Z: GEPIA: A web server for cancer and normal gene expression profiling and interactive analyses. Nucleic Acids Res 45: W98-W102, 2017.

11. Livak KJ and Schmittgen TD: Analysis of relative gene expression Data using real-time quantitative PCR and the 2-(Delta Delta C (T)) method. Methods 25: 402-408, 2001.

12. Lewis CE and Pollard JW: Distinct role of macrophages in different tumor microenvironments. Cancer Res 66: 605-612, 2006.

13. Kessenbrock K, Plaks V and Werb Z: Matrix metalloproteinases: Regulators of the tumor microenvironment. Cell 141: 52-67, 2010.

14. Zhang W, Yuan W, Song J, Wang S and Gu X: LncRNA CPS1-IT1 suppresses EMT and metastasis of colorectal cancer by inhibiting hypoxia-induced autophagy through inactivation of HIF-1 $\alpha$. Biochimie 144: 21-27, 2018.

15. Li J, Yang B, Zhou Q, Wu Y, Shang D, Guo Y, Song Z, Zheng Q and Xiong J: Autophagy promotes hepatocellular carcinoma cell invasion through activation of epithelial-mesenchymal transition. Carcinogenesis 34: 1343-1351, 2013.

16. Galavotti S, Bartesaghi S, Faccenda D, Shaked-Rabi M, Sanzone S, McEvoy A, Dinsdale D, Condorelli F, Brandner S, Campanella M, et al: The autophagy-associated factors DRAM1 and p62 regulate cell migration and invasion in glioblastoma stem cells. Oncogene 32: 699-712, 2013.

17. Fan D, Liu SY, van Hasselt CA, Vlantis AC, Ng EK, Zhang H, Dong Y, Ng SK, Chu R, Chan AB, et al: Estrogen receptor $\alpha$ induces prosurvival autophagy in papillary thyroid cancer via stimulating reactive oxygen species and extracellular signal regulated kinases. J Clin Endocrinol Metab 100: E561-E571, 2015.

18. Wang W, Kang H, Zhao Y, Min I, Wyrwas B, Moore M, Teng L, Zarnegar R, Jiang X and Fahey TJ III: Targeting autophagy sensitizes BRAF-Mutant thyroid cancer to vemurafenib. J Clin Endocrinol Metab 102: 634-643, 2017.

This work is licensed under a Creative Commons Attribution-NonCommercial-NoDerivatives 4.0 International (CC BY-NC-ND 4.0) License. 